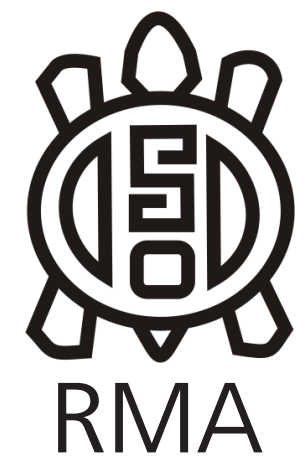

Antropología Social

\title{
Misiones evangélicas, capitalismo y regulación estatal entre los guaraníes del Noroeste Argentino
}

\author{
Evangelical missions, capitalism and state regulation among the \\ Guarani of the Argentine Northwest \\ Mariana Espinosa
}

CONICET, Instituto de Antropología de Córdoba, Universidad Nacional de Córdoba, Argentina, e-mail: marianaestherespinosa@gmail.com

\begin{abstract}
Resumen
El evangelismo entre guaraníes del Noroeste Argentino es un tema poco explorado que sería importante vitalizar dado su alcance geográfico, profundidad histórica e impacto socio-cultural contemporáneo. El presente artículo amplia y complementa conocimiento histórico y etnográfico sobre la expansión de misiones evangélicas de origen británico y norteamericano entre los guaranies, evidenciando tres momentos de los emprendimientos misioneros y su relación con el Estado y los establecimientos agro-industriales, entre 1890 y 1980. Es principalmente la búsqueda de comprensión y explicación del actual mapa de iglesias evangélicas guaraníes lo que nos lleva a plantear un estudio de larga duración sobre la génesis y las transformaciones del sistema socio-cultural organizado por la expansión del evangelismo entre comunidades indígenas de la región. El desarrollo del artículo combina fuentes documentales, observaciones etnográficas y un sistema de referencias bibliográficas pertinentes.
\end{abstract}

Palabras claves: Misiones evangélicas; Guaraníes; Capitalismo; Regulación estatal; Noroeste Argentino.

\begin{abstract}
Evangelism among the Guarani of Argentina Northwest is a subject of study scarcely explored that would be important to vitalize given its geographical scope, historical depth and contemporary socio-cultural effects. This article broadens and complements historical and ethnographic knowledge about the expansion of evangelical missions of British and North American origin among the Guarani, putting in evidence three moments of the missionary undertakings and their relationships with the State and the agro-industrial companies, between 1890 and 1980. It is mainly the search for understanding and explanation of the current map of evangelical Guarani churches that leads us to propose a long-term study on the genesis and transformations of the socio-cultural system organized by the expansion of evangelism among indigenous communities in the region. The article combines historical sources, ethnographic observations and pertinent bibliographical references.
\end{abstract}

Keywords: evangelical missions; Guarani; Capitalism; State regulation; Argentine Northwest

En el ecotono entre Yungas y Chaco del Noroeste Argentino, más precisamente en sus zonas urbanas y periurbanas correspondientes a las provincias de Jujuy y Salta, puede advertirse la extendida presencia de iglesias evangélicas en cuyos frentes se puede leer "Local Evangélico", "Iglesia Cristiana Evangélica", "Iglesia Cristiana Bautista" y otras combinatorias con las cuales comunidades indígenas y evangélicas se inscribieron progresivamente en el Registro Nacional de Cultos a partir de su creación en el año 1978. Las familias e individuos que a éstas concurren son, en gran medida, guaraníes. Entre ellos, la mayoría trabajó o trabaja en los ingenios azucareros del piedemonte. Aunque los estudios sobre el contacto entre misioneros e indígenas y evangelismo étnico son abundantes, especialmente en la etnografía y la etnohistoria chaqueña (Wright,2002; Demera,2009;
Ceriani Cernadas, 2015a), los procesos de misionalización dirigidos hacia guaraníes es un área de estudio poco explorada y que sería importante vitalizar dado su alcance geográfico, profundidad histórica e impacto socio-cultural contemporáneo. ${ }^{1}$

En este artículo me propongo esbozar tres momentos socio-históricos de la presencia misionera evangélica de origen británico y norteamericano entre los guaraníes del NOA. Anima este propósito una etnografía histórica que llevo adelante sobre el tema y que me ha permitido

\footnotetext{
${ }^{1}$ Rita Segato (2007) y Claudia Lozano (2001) estudiaron la presencia de hermanos libres y bautistas entre grupo collas de la Quebrada y la Puna. Por mi parte, investigué la presencia de los hermanos libres entre guaraníes al interior del ingenio La Esperanza (Espinosa, 2015; 2017). Estos son los antecedentes de investigación recabados hasta el momento.
} 
reconocer al menos tres momentos diferenciables en los procesos de misionalización de dos de las actuales denominaciones más arraigadas en la zona; hermanos libres y bautistas. Dicha diferenciación se vincula a diferentes estados en las relaciones entre misioneros, enclaves agro-industriales, particularmente los ingenios azucareros del piedemonte, y las formas en que el Estado se hizo presente en cuanto a la regulación ${ }^{2}$ de la diversidad indígena y religiosa de la región (Giumbelli, 2016:19). No se trata apenas de establecer fechas y predefinir periodos estancos, es principalmente la búsqueda de comprensión y explicación del actual mapa de iglesias evangélicas guaraníes lo que nos lleva a plantear un estudio de largo plazo sobre su gestación que abarque procesos como el arribo y los desplazamientos misioneros más importantes, las reterritorializaciones guaraníes y otras transformaciones en el marco de una economía de enclave y la memoria de los actuales pobladores.

En efecto, el artículo se divide en tres partes. Primero, introduzco el proceso de misionalización emprendido por misioneros británicos Plymouth Brethren, conocidos en Hispanoamérica como "hermanos libres" que llegaron a San Pedro de Jujuy a fines del siglo XIX y establecieron una misión entre guaraníes al interior del ingenio azucarero La Esperanza. A continuación, abordo la llegada a la misma región en 1948 de misioneros bautistas norteamericanos de la Conservative Baptist Foreign Mission Society. En el último apartado, centro mi atención en la experiencia de los guaraníes en torno a los años comprendidos entre1960 y 1980; aquí emergen los efectos de la presencia superpuesta de los misioneros británicos y norteamericanos, sus acuerdos y sus futuras diferenciaciones, una nueva fase del ingenio azucarero y los efectos del nuevo Registro Nacional de Culto.

Recurro a fuentes documentales, bibliográficas y etnográficas. En cuanto a las fuentes documentales, utilizo algunos números de la publicación mensual El Sendero del Creyente y también informes misioneros. Trabajo con bibliografía especializada y apologética. Finalmente, recurro a notas de campo y registros sonoros de encuentros mantenidos con pobladores de La Esperanza, San Pedro, Cherenta y Tartagal (centro). Espero

\footnotetext{
${ }^{2}$ Giumbelli pone en cuestión una visión de la "regulación de lo religioso" por parte del Estado que se polariza entre acciones que privilegian o restringen el desarrollo de grupos religiosos. Se inspira en Foucault para proponer la idea de regulación no como una anomalía sino como una propiedad del sistema. Indica que "regulación, en cuanto concepto para las ciencias sociales de la religión, puede ser usado para designar los mecanismos por los cuales, a partir de cierta definición de lo 'religioso', éste es constituido por la conjunción de acciones de diversos actores" (2016:17). Finalmente, señala que "lo más importante, no es determinar el grado de regulación sino las correspondencias entre ciertas concepciones de religión y la definición de fronteras que diseñan, de una u otra forma, el campo religioso y la relación entre actores religiosos y no religiosos (2016:19, las traducciones son mías). Si bien el Estado no es foco de este trabajo, sino las acciones misioneras intersectadas por el Estado y el desarrollo de una economía enclave, retenemos esta noción que será aprovechada al final del trabajo.
}

que esta revisión sobre la presencia misionera euronorteamericana en el NOA genere nuevos interrogantes sobre las relaciones entre religión, capitalismo y Estado como vectores de las transformaciones del mundo indígena bajo un régimen neocolonial. A su vez, quisiera aportar a la comprensión de facetas poco exploradas de la actual diversidad cultural y religiosa en la región y contribuir a las reflexiones sobre el pasado que los guaraníes llevan a adelante en el marco de diversos procesos de comunalización.

\section{Los hermanos libres y el ingenio La Esperanza: una afinidad electiva (primeras décadas del siglo XX)}

Una parte considerable de los grupos protestantes que llegaron a la Argentina entre fines del siglo XIX y principios del XX fue de carácter evangélico y desarrollaron sus misiones en el contexto de creciente expansión de un proyecto económico y cultural neocolonial que implicó la incorporación subordinada de la región al capitalismo mundial, la expansión del Estado nacional y la conquista y colonización de áreas consideradas "desiertas". El Estado, exterminó, en algunos casos, y disciplinó forzosamente, en otros, sociedades indígenas de todas las latitudes. El NOA y en particular la subregión bajo foco se encontraba en transformación como efecto de la modernización de los antiguos ingenios azucareros, fenómeno ligado a su vez con la conquista militar del Chaco (1884) y la extensión del ferrocarril a las ciudades norteñas (Teruel 2005). A este escenario arribaron los misioneros hermanos libres a la Argentina.

Los hermanos libres surgen en Gran Bretaña en 1825 en contra del clericalismo de las iglesias establecidas del Imperio. El carácter asambleario y la disolución de la figura de un clero ordenado moldearon el movimiento en su génesis. En la Argentina se definieron mayormente a partir de una cristología soteriológica que enfatiza al Cristo trascendente en detrimento del Jesús histórico; importancia dada a la santificación, en términos de la separación del mundo y consagración a Dios del creyente; una eclesiología congregacional; y una escatología dispensacional que plantea la eminente segunda venida de Cristo, pero antes de la tribulación el rapto de su iglesia, momento en el cual se llevaría a los santos (Roldan, 1996).

A partir de 1882 llegan a la Argentina misioneros y misioneras de este movimiento, en su mayoría británicos. En el país cultivaron lazos con sus connacionales lo que les permitió ocupar diferentes puestos en los ferrocarriles. ${ }^{3}$

\footnotetext{
3 Un caso paradigmático fue el del misionero Willian Charles Kirkby Torre que al llegar al país formó parte del personal del Ferro Carril de Buenos Aires y Ensenada, como Secretario del Jefe de Tráfico y luego Jefe de ese departamento. Después de estos puestos pasó a ocupar el cargo de contador de los contratistas del Puerto de Buenos Aires Sres. C.H. Walker y Co. Anonimo, "William Charles Kirkby Torre" El Sendero del Creyente, $1923 n^{\circ} 11$, p. 242. Por otro lado, A. Clifford a los $90^{\circ}$ de los hermanos libres en el país dedica un artículo al nombrado misionero agregando más información sobre el tema: "Don Carlos
} 
De allí que la extensión de los rieles, entre otros factores, trazó la fundación de misiones e iglesias en un recorrido que fue desde Río de la Plata hasta las provincias del Noroeste (Bianchi, 2004; Espinosa, 2014). Hacia 1911 los hermanos libres contaban con 24 asambleas en la Argentina, a las que habría que sumar casas de oración, hospicios, editoriales, imprentas, etc. La innovación en técnicas de misionalización y la colaboración interdenominacional facilitaron la implantación del protestantismo evangélico en el país (Canclini, 2003; Espinosa, 2014).

Las empresas de ferrocarriles no sólo fueron importantes para trazar una ruta inicial. En el marco de un modelo eclesial congregacional y lejos del sostén imperial, a fin de estabilizar materialmente sus misiones, iglesias y anexos, los misioneros aprovecharon su relación con dichas empresas y potenciaron los beneficios de aquel círculo de sociabilidades ${ }^{4}$ y de una primera camada de inmigrantes conversos que, a través de diversos negocios, se montaron a la carrera de ascenso económico. Más allá de los aportes económicos que recibían de las iglesias de origen, fueron especialmente estas alianzas las que encaminaron la expansión y estabilización de los hermanos libres en la Argentina. De manera directa un informe misionero destaca que el éxito de sus obras en el país estuvo ligado a los "business brethren"; creyentes vinculados a medianas y altas esferas de las empresas de capitales externos que emergían en el primer cuarto del siglo XX (Stunt et al., 1972:231).

La introducción de este grupo de misioneros entre los guaraníes del NOA no es una excepción a esta tendencia. Al contrario, allí aparece más claramente la ligazón, como afinidad electiva weberiana, entre capitalismo y protestantismo. Dicha expansión se inició en 1887 con la llegada de John Linton al ingenio azucarero La Esperanza de la familia inglesa Leach, ubicado en San Pedro de Jujuy, en el piedemonte jujeño. En 1908 llegó el misionero Thomas Easdale quien contrae matrimonio

Torre fue el primero de una serie de creyentes ingleses que ocuparon cargos humildes o importantes en los ferrocarriles para la pagar los gastos de su consagrada labor cristiana. ¡Cuántas asambleas deben su existencia indirectamente a estos caballeros del riel! Recordemos los nombres de algunos de éstos: Ernesto Airth, Federico Coleman, Jorge Spooner, Walter Pender, Jaime Pender, Jaime Kirk, Roberto Hogg y Nigel Darling en los primeros años." Clifford A., El Sendero del Creyente, 1972, n5, p. 130-131.

${ }^{4}$ A. Clifford escribe en 1972: "En la fundación y obra del orfanatorio fueron ayudadores los esposos Barnett y también el doctor Fleming, íntimos amigos de don Carlos. El hermano Fleming, pastor presbiteriano escocés, asesoraba continuamente a los esposos Torre y consiguió el apoyo financiero de la colectividad británica. El hermano Barnett, un acaudalado anglicano residente en Soldini, cerca de Rosario, ayudó con fuertes donaciones. Es necesario destacar que muchos de los locales de predicación nuestras asambleas en la Argentina de los primeros años se levantaron merced a la ayuda de desinteresada del hermano Barnett que, aunque anglicano, no se preocupaba de los rótulos denominacionales y veía a un hermano en cada ser redimido por Cristo." Clifford A., El Sendero del Creyente, 1972, n5, p. 130131. Sobre un estudio más detallado del proceso de misionalización de los hermanos libres en la Argentina véase Espinosa (2014). con la Elisabeth Linton, hermana del anterior. Los dueños del ingenio dieron casa a los Easdale y las tierras para establecer la misión al interior de la fábrica de azúcar, dicho lugar fue bautizado como Cherenta (mi casa) (Easdale, 1988:93).

Por su ubicación geográfica, esta misión fue un punto estratégico para expandir el mensaje evangélico entre grupos indígenas del ecotono entre Yunga y Chaco, pero también para el circuito misionero del NOA en general y para ultrapasar las fronteras nacionales. Recordemos que a los ingenios de Salta y Jujuy confluía una enorme diversidad de grupos indígenas del norte de Argentina y sur de Bolivia (Lagos, 1992). El Estado, a través de sus fuerzas represivas, debía garantizar el funcionamiento de los sistemas de "enganche" y la "seguridad" como condición para el éxito comercial (Rutledge, 1987; Bossert y Córdoba, 2015).El objetivo de los patrones era crear una estructura laboral que permitiese la mayor productividad. Para ello sometieron a los indígenas a condiciones infrahumanas de trabajo dejando secuelas físicas, psíquicas y socio-culturales y causando el deceso de cientos de ellos. ${ }^{5}$

En Jujuy, a inicios de siglo XX el grueso de los trabajadores temporarios eran wichís, tobas, chorotes y otros indígenas del Gran Chaco como así también grupos indígenas de la Quebrada y la Puna. Entre los permanentes, la mayoría eran criollos y diferentes grupos de lengua guaraní. En los sectores de fábrica, talleres y acarreo también predominaban guaraníes. ${ }^{6}$ Esta división del trabajo encontraba correlación en la distribución espacial de los grupos en los ingenios. En los primeros años del siglo $\mathrm{XX}$ en La Esperanza los grupos provenientes del Chaco vivían en tolderías transitorias ubicadas alrededor de los campos de plantación, mientras que los grupos de lengua guaraní habitaban en lugares más cercanos a la fábrica y en casillas y galpones puestos por los patrones (Lagos, 1992; Bossert, 2012).

A sabiendas de este esquema, los misioneros evangelizaban en dichos alrededores denominados "lotes". Hoy en día, algunos lotes se convirtieron en barrios, cuya distancia en relación a la fábrica y a la vivienda de los patrones permite entrever en la ocupación del espacio las jerarquías interétnicas y laborales pasadas. Los lotes constituían puñados de hectáreas con población permanente y transitoria en la época de zafra. Cada

\footnotetext{
${ }^{5}$ La bibliografía sobre el tema es amplia. Véase p.e. la compilación de Daniel Campi (1992) y para los ingenios salto-jujeños los trabajos de Lagos (1992) y Santamaría (1992) allí editados. Una etnografía histórica sobre el tema puede verse en Bossert (2012 y 2013) y Bossert y Córdoba (2015). Etnografía chaqueña dedicada al trabajo y/o migraciones indígenas a los ingenios véase: Langer (1995); Hirsch (2004); Gordillo (2010a), Gómez (2010) Ceriani Cernadas (2015b), Montani (2015), entre otros.

${ }^{6}$ A los fines de nuestra exposición, estamos dejando de lado diversos grupos indígenas, inmigrantes de provincias del NOA y trasatlánticos que constituyeron el amplio arco de trabajadores de los ingenios jujeños durante la primera mitad del siglo XX.
} 
lote a su vez conformaba cierta unidad relativamente autónoma puesto que se definía por el predominio de un grupo étnico, también podían convivir allí dos grupos o más en época de zafra. Dicho predominio es palpable hoy en día en las extensas parentelas que allí viven de modo permanente. Los hermanos libres actuaron correlativamente a estas redefiniciones espaciales efectos de las economías de enclave. El siguiente cuadro muestra la expansión evangélica de los hermanos libres entre guaraníes hasta 1950. Más precisamente los lugares en donde identifiqué misioneros y misioneras de modo permanente hasta ese año. También allí se puede ver el periodo en que dichos agentes estuvieron en la Argentina.

De acuerdo a lo expresado acerca del patrón de desplazamientos y emplazamientos, podemos decir que los hermanos libres fueron funcionales al asentamiento y pacificación de la fuerza de trabajo indígena. Esta posición de los misioneros, también encontraba resortes en el llamado "Segundo Despertar" que influyó en la definición de los aspectos doctrinales arriba esbozados. De acuerdo a Míguez Bonino al menos hasta laPrimera Gran Guerra, el protestantismo misionero en América Latinaera:

(...) básicamente evangélico, (...) individualista, cristológico-soteriológico en clave básicamente subjetiva, con énfasis en la santificación. Tiene un interés social genuino, que se expresa en la caridad y laayuda mutua pero que carece de perspectiva estructural y política excepto en lo que toca a la defensa de su libertad y la lucha contra las discriminaciones; por lo tanto tiende a ser políticamente democrático y liberal, pero sin sustentar tal opción en su fe ni hacerla parte integrante de su piedad" (1995:46).

Creemos que estas ideas, no de un modo lineal, generaron un tipo de actitudes en los misioneros, sus misiones y futuras congregaciones. La misión de La Esperanza en varias oportunidades es referenciada en las fuentes como "la parte social" de las acciones que desarrollaban los hermanos libres en el país. En la práctica misionera esto implicaba, por un lado, una actitud de reforma social a través de la educación, como la iniciación en la cultura escrita, y por otro lado, la reforma moral mediante la transmisión del mensaje de Salvación como única vía de resolución de una situación de opresión. A la salvación le seguía la inducción a la santificación, esto es, la demarcación de una nueva comunidad de pertenencia progresivamente apartada de los asuntos del mundo. Esto significaba un acercamiento al indígena desde una perspectiva etnocéntrica que era funcional a las demandas de disciplinamiento laboral por parte de los patrones azucareros. Asimismo, referirse a las misiones indígenas como "la parte social", no implicaba escatimar esfuerzos misioneros para concentrarlos en "otras partes", puesto que aquellas se desarrollaban en la arena de relaciones que alimentaba la expansión evangélica; el vínculo con agentes capitalistas. 


\section{La llegada de bautistas norteamericanos (mediados del siglo $\mathrm{XX}$ )}

En 1948 llegan a San Pedro de Jujuy misioneros bautistas norteamericanos que pertenecían a la Conservative Baptist Foreign Mission Society. La argentina de inicio de siglo había cambiado; las zonas de acción y las bases sociales a las cuales se dirigían los misioneros no eran las mismas. El gobierno militar que llegó al poder en 1943 al año siguiente creó la Ley 12.912 más conocida como El Estatuto del Peón: en este marco se elevaban los salarios y el Estado pasaba a regular las condiciones de los contratos laborales, también se exigía a las empresas proveer de alimentos a precio justo, viviendas y asistencia médica a los trabajadores. Sin embargo, indica Rutledge, "sería ingenuo creer que aquellas cláusulas que favorecían al trabajador, eran siempre rigurosamente cumplidas por el contratista y por el ingenio" (1987: 215). Pero también agrega que "entre 1943 y 1955, dejaron de tener vigencia algunos de los aspectos más desembozadamente coercitivos del trabajo en las plantaciones" (1987:216). ${ }^{7}$ Parte de estas transformaciones son plausibles en la memoria de actuales pobladores de La Esperanza y San Pedro que al tiempo que recuerdan el trabajo extremadamente duro y muchas injusticias cometidas también recuerdan un tiempo en el cual accedían a bienes con mayor facilidad y recibían mejor atención a la actual en términos de salud, vivienda y educación. Sin embargo, estas representaciones también se entrelazan con facetas del tiempo de los Leach; los empresarios en grados variables tuvieron un accionar subsidiario a las competencias de un Estado. Los apologistas de turno enaltecieron dichas actuaciones como motores de modernización y civilización en San Pedro y sus alrededores. ${ }^{8}$

En el mismo periodo el Estado nacional impulsó políticas de regulación de expresiones religiosas. De la mano de la Pastoral Colectiva del Episcopado había crecido la crítica eclesiástica hacia los protestantes impugnados por extranjeros y extranjerizantes. Los intelectuales del periodo, tanto religiosos como laicos, promovieron una suerte de nacionalismo religioso que debía asegurar el predominio de una población latina y católica (Bianchi 2004; Catoggio, 2008). Iniciado el primer gobierno de Perón, se acentuaron dichos discursos. En este marco, en 1948 se creó un registro de cultos no católicos llamado "Fichero de Cultos" que prohibió el funcionamiento de cualquier centro religioso que no estuviera inscripto. Al año siguiente, el gobierno avanzó con un proyecto de reforma constitucional que establecía que el Ministerio de

\footnotetext{
${ }^{7}$ Curiosamente, para ratificar esta idea, Rutledge retoma un testimonio de un hombre chiriguano (guaraní) trabajador del ingenio Tabacal para ratificar esta idea.

${ }^{8}$ En otros trabajos nos explayamos sobre las memorias actuales de los guaraníes del proceso misional en donde afloran representaciones sobre el "progreso" y "civilización", convergentes al imaginario neocolonial inherente al desarrollo de una economía de enclave (Espinosa, 2015).
}

Relaciones Exteriores y Culto debía, además de garantizar el libre ejercicio del culto, "fiscalizar" a las organizaciones e "intervenir si fuera necesario" (Bianchi, 2004). Asimismo, durante este mismo gobierno, desde la Comisión Nacional de Zonas de Seguridad se prohibió iniciar nuevas obras misioneras y edificar templos entre grupos indígenas del Gran Chaco y algunas misiones preexistentes fueron suspendidas (Lunt ibid.:57; Ceriani Cernadas, 2017). ${ }^{9}$

A partir del marco anteriormente descripto es posible interpretar que a los bautistas se les había achicado el campo misionero. De este modo se torna más comprensible que San Pedro y los poblados cercanos tanto de Jujuy como de Salta hayan sido un primero y seguro mojón para los nuevos misioneros. Otra hipótesis por esta preferencia socio-geográfica puede ligarse al mapa bautista general de la Argentina. La camada de misioneros norteamericanos que llegaron a la zona provenía de un movimiento bautista diferente al ya establecido en el país. El referido grupo había cristalizado en 1908 en la Convención Evangélica Bautista y que se concentraba sobre todo en Santa Fe, Buenos Aires, Mendoza, San Juan y Córdoba (Junta Bautista de Publicaciones, 1959). La génesis de la Conservative Baptist Foreign Mission Society, de donde provenían los misioneros que llegaron al NOA, se remonta a 1943 en Chicago y corresponde una importante fisión entre bautistas en Estados Unidos. El naciente grupo cuestionaba lo que consideraban "liberalismo" teológico y buscaba "conservar" la verdad de la Biblia. El interés misionero se asocia a la crítica infligida por la renovación doctrinal de misioneros formados en corrientes que suponían formas críticas e historizadas de leer las Escrituras. Ante esta "amenaza", nació el impulso misionero de una nueva agrupación. ${ }^{10}$ Antes de focalizarnos en el recorrido y actuación de los misioneros bautistas en el NOA, veamos una tabla con información de los dos grupos de misioneros que nos ocupan (Tabla 2).

Los hermanos libres que habían iniciado su expansión en el país a fines del siglo XIX hacia 1957 contaban con 53 misioneros y misioneras. De los cuales al menos 20 eran matrimonios misioneros y el resto misioneras solteras y algunos viudos, en su gran mayoría se trataba de personas longevas distribuidas en el elevado número de 319 cultos -o donde de manera habitual se celebra un acto público-concentrados principalmente en diferentes provincias del Río de Plata, Litoral, Centro y NOA. Por

\footnotetext{
9 Las relaciones del peronismo con las minorías religiosas no se reducen a estas acciones. Soledad Catoggio resume algunas de las lecturas sobre este tema, entre ellas la de Cucchetti, para quien el peronismo se arrogó "de un poder simbólico de lo sagrado que le permitió no sólo entrar en diálogo cómodamente con otros agentes religiosos, sino emprender un proceso de desestructuración jerárquica de lo religioso". Esta tesis es consecuente con la lectura de que, por un lado, el gobierno promovió algunos grupos religiosos y, por el otro, optó por acciones legalistas de control (Catoggio, 2008). Además de lo citado, véase Di Stéfano y Zanatta (2000) y Bianchi (2004).

10 https://www.worldventure.com/about/history/ (Última consulta13/05/2017).
} 


\begin{tabular}{llllll}
\hline Sociedad misionera & Cultos & \multicolumn{2}{c}{ Misioneros Extranjeros } \\
Varones & Mujeres & Obras consolidadas & Lugares de expansión \\
\hline $\begin{array}{l}\text { Plymouth Brethren/ } \\
\text { Hermanos Libres }\end{array}$ & 319 & 23 & 30 & $\begin{array}{l}\text { Buenos Aires; Santa Fe; } \\
\text { Córdoba; Santiago del } \\
\text { Estero; Tucumán; Salta; } \\
\text { Jujuy; San Luis; } \\
\text { Mendoza; San Juan }\end{array}$ & $\begin{array}{l}\text { Rio Negro, Neuquén, } \\
\text { Chubut, Tierra del Fuego. } \\
\text { Misiones; Entre Rios }\end{array}$ \\
\hline $\begin{array}{l}\text { Conservative Baptist, } \\
\begin{array}{l}\text { Missionary Society/ } \\
\text { Bautistas }\end{array}\end{array} 40$ & 12 & 14 & Jujuy; Salta; Tucumán. & \\
\hline
\end{tabular}

Tabla 2. Hermanos libres y bautistas en la Argentina en 1957. La variable “cultos" refiere a "no sólo las construcciones, capillas o iglesias, sino también todo lugar donde de un modo habitual se reúna una comunidad para celebrar algún acto público" (Damboriera, 1963:17). Fuentes: Elaboración propia a partir de Bingle \& Grubb (eds) World Christian Handbook, Londres, 1957 en Damboriera, Prudencio.El protestantismo en América Latina (tomo II). Madrid: Oficina Internacional de Investigaciones Sociales de FERES, 1963, p.43; Stunt, W.T. et al Turning the world upside down. Bath, Echoes of service, Upperton press, 1972; Bisio, Carlos, Nuestros Primeros Pasos, Buenos Aires, Librería Editorial Cristiana, 1982; y a la Dirección Nacional del Registro Nacional de Cultos del Ministerio de Relaciones Exteriores y Culto de la Nación.

Table 2. Sources: Own elaboration from Bingle \& Grubb (eds) World Christian Handbook, London, 1957 in Damboriera, Prudencio. El Protestantism in Latin America (volume II). Madrid: International Bureau of Social Research of FERES, 1963, p.43; Stunt, W.T. et al Turning the world upside down. Bath, Echoes of service, Upperton press, 1972; Bisio, Carlos, Our First Steps, Buenos Aires, Librería Editorial Cristiana, 1982; and the National Directorate of the National Registry of Worship of the Ministry of Foreign Affairs and Worship of the Nation.

el bajo número de misioneros en relación al total de cultos y por fuentes bibliográficas es posible afirmar que para entonces la totalidad de las misiones e iglesias consolidadas contaban con líderes nacionales, inclusive allí en dónde había misioneros extranjeros (veáse Tabla 2). Esta información es congruente con la lectura de Bisio, anciano e historiador hermano libre quien señaló que en el marco de los sucesos de la década de 1940

(...) la ciudadanía británica de nuestros misioneros provocaría una tácita objeción de los componentes criollos en las asambleas. Proceso que permitirá ver que, iniciada la década de 1960, el liderazgo en la gran mayoría de las congregaciones era ejercido por elementos nativos y descendientes de las distintas oleadas inmigratorias (Bisio, 2007: 179).

Roberto Jack, hijo de misioneros británicos, por su parte indicó que el proyecto misionero de los hermanos libres "fue perdiendo ímpetu, en particular en la Argentina de posguerra. Se llegó a cristalizar como obra de extensión misionera. Pero creció en profundidad y en autogestión, siendo totalmente autónoma del exterior" (Jack, 2007: 167). Por su parte los misioneros de la Conservative Baptist Missionary Society, sumaban 26, la mayoría matrimonios concentrados en Jujuy y Salta. Sabemos que en 1948 llegan a San Pedro dos matrimonios misioneros. ${ }^{11}$ De acuerdo a Lozano entre 1957 y 1984 actuaron los matrimonios misioneros Gerow, Ferguson y Johns (Lozano, 2001:54).12 Las memorias de guaraníes y criollos de la zona reverberan los nombres de las familias Gerow,

\footnotetext{
11 A gradecemos por esta información a la Dirección Nacional del Registro Nacional de Cultos del Ministerio de Relaciones Exteriores y Cultos de la Nación.

12 Sin bien Lozano (2001) circunscribe su trabajo a las regiones de la Quebrada y la Puna del NOA, a partir de ahora retomamos parte de la información que ofrece puesto que los nombres de los misioneros que ella destaca corresponden a los mismos que hemos anotado en entrevistas con guaraníes y criollos del piedemonte y occidente de Chaco.
}

Ferguson, MacPhersons y Hoops. También se recuerda que los misioneros británicos se destacaron como buenos anfitriones de los norteamericanos.A nuestro juicio, también debe tenerse en cuenta la situación de transición de las obras misioneras de los hermanos libres como apertura a la colaboración interdenominacional.

En efecto, a los misioneros y misioneras norteamericanos se los observa evangelizando en las obras misioneras de los hermanos libres en los pequeños poblados que ya se habían formado por efecto de los ingenios del piedemonte salto-jujeño, en donde se destacaba la presencia de guaraníes, como puede verse en la actualidad. Siguieron la línea del "ramal jujeño" y se extendieron por el ramal Embarcación-Pocitos llegando a comunidades guaraníes del ejido de las ciudades Tartagal y Aguaray.En terreno observé que un número considerable de sitios donde ya se habían levantado iglesias o era regular la celebración de un culto (ver Tabla 1) luego pasaron a ser gestionados por bautistas. Más adelante veremos testimonios sobre esta "superposición". Así también los bautistas avanzaron sobre nuevos pueblos y barrios de la misma región.De manera paralela en los trabajos de Segato (2007) y Lozano (2001) encontramos que los misioneros que circulaban los valles subtropicales también seguían el circuito de los hermanos libres en la Quebrada y la Puna entre grupos collas, en algunos casos trabajadores de la zafra y en otros de las explotaciones mineras. Hasta 1953, los misioneros norteamericanos actuaron casi exclusivamente en Jujuy y Salta y a partir de entonces de expanden hacia la provincia de Tucumán. ${ }^{13}$

Ahora bien, la misión bautista promovía los mismos rituales y estructura eclesial que los hermanos libres: énfasis en la cena del Señor; estudio bíblico; rechazo a la figura del ministro ordenado en favor de que cualquier

\footnotetext{
13 Agradecemos por esta información a la Dirección Nacional del Registro Nacional de Cultos del Ministerio de Relaciones Exteriores y Culto de la Nación.
} 
miembro inspirado pueda orar y predicar; en cuanto a los pastores a cargo, responde a un "llamado" divino (Lozano, 2001:52). En otro orden de cosas también es preciso señalar que al igual que los hermanos libres, los bautistas se acercaron a comerciantes, empresarios y funcionarios $u$ otros actores de influencia en la escena local (Lozano, 2001:55), aunque posiblemente por razones diferentes.

Lozano, quien accedió a párrafos (previamente editados) de las cartas enviadas por el misionero Carlos Gerow a sus familiares y centro misionero en los EE. UU, indica que las mismas "abundan en relatos sobre personas que dejaban de beber, de robar y de tomar drogas (hojas de coca) para convertirse en trabajadores responsables, atractivos para sus patrones" (Lozano, 2001: 54-55). Así también, se considera que "la fuente del malestar es el deseo incontrolado producido por influencias demoníacas. Frente a ello, los misioneros proponen la conversión de personalidades regidas por la carne, el demonio la culpa y la falta de sentido en personalidades controladas por la voluntad de vivir la vida en el perdón de Cristo" (Shelley, 1973:11-12 en Lozano, 2001:52).

Las diferencias de los proyectos misionales de hermanos libres y bautistas se comprenden en los marcos sociales, políticos y económicos de sus acciones. La actuación de los primeros incluía mayormente la incorporación de prácticas y valores relativos a la cultura escrita, el aseo personal, la familia nuclear y la cultura tradicional -considerada pagana y/o producto de sincretismos-, rudimentos, al mismo tiempo, para el disciplinamiento laboral. Los bautistas conocen a una población demográficamente mucho más densa y en grados considerables de hacinamiento. ${ }^{14}$ En este contexto, los misioneros resaltan problemas de violencia doméstica, "flojera" frente al trabajo y redes de tipo "clientelar" e instan a los trabajadores a que dejen que Dios obre en todos los aspectos de sus vidas (Lozano, 2001:54). En esos años empezaba a visibilizarse el grave problema de la desocupación.

El acercamiento entre hermanos libres y bautistas, tomará otro rumbo en las décadas de 1960 y1970, años de nuevas transformaciones en el campo evangélico. Entre los factores más importantes, en cuanto a sus efectos en la Argentina, hay que señalar: el crecimiento pentecostal y neopentecostal; el movimiento de "renovación" al interior de hermanos libres y bautistas; las tendencias ecuménicas de algunos grupos protestantes; y la creación del Registro Nacional de Cultos (1978), como nueva instancia de demarcación de fronteras al interior del campo protestante en general.

\footnotetext{
${ }^{14}$ Entre 1895 y 1947 se pasó de 49.713 pobladores jujeños a 166.700. San Pedro presentó un crecimiento interesal sostenido, quizás producto de las empresas azucareras. De cualquier modo por ejemplo San Pedro creció entre 1914 y 1947 un 198\% (es preciso indicar que no hay información para La Esperanzani La Mendieta para el año 1914, si para 1947). En 1943, la zona del Ramal jujeño presentaba el mayor porcentaje de hacimiento individual (60,2\%) (Jerez, 2010: 29-30-60).
}

\section{Iglesias y federaciones evangélicas entre desalojos y nuevas migraciones guaraníes (1960 - 1980)}

En este apartado intentaré mostrar, a través de registros etnográficos y las memorias de los pobladores, los efectos la presencia de los misioneros británicos y norteamericanos, sus acuerdos, transformaciones y diferenciaciones y algunas características de las iglesias evangélicas en un nuevo momento socio-histórico. Antes de avanzar es preciso señalar algunos procesos que harán más comprensibles la narrativa de los guaraníes.

De acuerdo a Rutledge a partir de 1953 la industria azucarera de Jujuy empieza a disminuir sistemáticamente el número de sus trabajadores tanto permanentes como transitorios. La creciente mecanización en las tareas agrícolas como la preparación de la tierra, el transporte manual de caña y mediante vías de tren Decauville fue reemplazada por elevadores de horquilla y camiones Kenworth de diez ruedas y la sustitución de pela manual de caña y por su quema. En La Esperanza, en la década de 1956 se empleaba alrededor de 5.000 trabajadores de campo estacionales y en 1966 se emplearon sólo 637(Rutledge 1987: 252-154). De esto modo se afectó no sólo a los aborígenes del Gran Chaco que año tras año migraban para la zafra sino también a aquellos grupos que vivían en los alrededores de los establecimientos, como el caso de los guaraníes. En este contexto las empresas desalojaron, desplazaron y re-ubicaron grupos de familias completas que originaron nuevas migraciones guaraníes tanto al interior de Jujuy como hacia Salta y Bolivia. ${ }^{15}$

El escenario evangélico argentino tampoco es el mismo en estos años. En las décadas del '50 y '60 en la Argentina se produjeron grandes campañas de sanidad y curaciones milagrosas de la mano de líderes carismáticos que dieron las bases para las transformaciones que suelen datarse con el retorno democrático y cuyo fenómeno conspicuo es el llamado "neopentecostalismo" (Wynarczyk, 1993; Algranti 2010). Esta situación puso en alerta a los hermanos libres, preocupados por la distorsión de la "sana doctrina". El pastor e historiador Carlos Bisio en el marco de una publicación por los 125 años de las asambleas en el país, escribe lo siguiente,

La generación que nos precedió tuvo que tomar una decisión, y lo hizo. A partir de la década de 1960, ante la confusión originada por la irrupción de movimientos interdenominacionales con compromisos

\footnotetext{
15 Un caso de este proceso puede verse en Gordillo (2010b). Aquí el autor analiza las acciones llevadas a cabo a partir del 2003 por comunidades guaraníes asentadas en poblados del ramal jujeño (la misma subregión abordada por nosotros) a fin de recuperar sus tierras. Se centra en comunidades guaraníes asentadas en barrios periféricos de las ciudades salteñas de Hipólito Yrigoyen y Pichanal que antes habitaban en La Loma y el Vinalito, tierras bajo la propiedad del ingenio El Tabacal y de las cuales fueron desalojados en los años de 1970. También remito al estudio de Pérez Bugallo (2013) que se centra en las memorias de los guaraníes de antigua misión franciscana de La Loma y del asentamiento forzoso en Pichanal.
} 
pentecostales y el avance del movimiento carismático, la mayoría de estos hermanos, preventivamente, revieron el alcance de sus respectivos ministerios. Transcurridos más de cuarenta años podemos decir que no se equivocaron. El desarrollo de los diversos dones de estos hermanos en medio de las asambleas es lo que ha permitido que el movimiento de los hermanos en Argentina llegara a sus 125 años con homogénea existencia (Bisio 2007:12).

Lozano informa que cuando los pastores norteamericanos abandonaron una iglesia de Humahuaca inició una crisis de autoridad. En los diagnósticos se venía que mientras algunos misioneros consideraban que su obra había producido transformaciones de vida otros consideraban que la gente no era "verdaderamente cristiana". Finalmente de estas tensiones surgiría la iglesia bautista renovada (2001:55). Fenómeno similar notaremos en el caso de los guaraníes.

A diferencia de los bautistas conversadores que ofrecen una comunicación con Dios basada en la lectura de la biblia, en la oración y en el soporte espiritual y material que las redes impulsadas por los misioneros produjeron, los hermanos bautistas de la renovación carismática ofrecen liberación de las aflicciones mundanas a través de la conexión persona con Dios (Lozano, 2001:56).

En este escenario, donde se puso en juego el "carácter evangélico" (la frase pertenece a Wynarczyk y Semán 1995), el gobierno militar promulgó y sancionó la ley 21.745 que dio creación al Registro Nacional de Cultos(RNC) en 1978 y que, aunque con modificaciones, continúa vigente. La ley determina que toda organización religiosa (menos la Iglesia Católica) debe inscribirse y cuyo reconocimiento condicionará su actuación. La denegación de este reconocimiento estatal implica la prohibición de actuar en el territorio nacional. ${ }^{16}$ Constreñidos y habilitados de la ley, que en su artículo $5^{\circ}$ posibilita la creación de organizaciones de segundo orden, los misioneros bautistas norteamericanos gestionaron la inscripción de la Sociedad Bautista Misionera en 1979. Un tiempo después, en 1988, los hermanos libres del país, en su totalidad argentinos, fundaron la Federación de Entidades Cristianas Evangélicas Argentinas (FECEA). ${ }^{17}$

A continuación transcribimos y analizamos recuerdos de pobladores de la Esperanza y San Pedro que afloraron principalmente en el año 2014. La presencia de los bautistas en la vida de los guaraníes de La Esperanza, la misión que por pionera y ubicación estratégica podemos decir que fue la más importante, inició un

\footnotetext{
16 Sobre esta ley y la regulación estatal en torno a minorías religiosas en la argentina puede verse Frigerio y Wynarczyk (2008) y López Fidanza (2014)

17 En 1995, FECEA cambia de nombre Federación de Iglesias e Instituciones Cristianas Evangélicas Argentinas (FICEA).
}

nuevo tiempo marcado por tensiones entre grupos familiares y liderazgos, pero también un nuevo impulso a la expansión de una identidad étnica-evangélica que parecía renovarse. Un hecho de trascendencia para los guaraníes de La Esperanza puede ayudarnos a objetivar el marco de relaciones que venía gestándose en la antigua misión por la presencia superpuesta de misioneros hermanos libres y bautistas y un nuevo ciclo de la usina industrial. Iniciada la década de 1970 y bajo el impulso de los misioneros bautistas, los creyentes trasladaron la iglesia de Cherenta que se encontraba en los terrenos del ingenio La Esperanza hacia el pueblo de San Pedro de Jujuy. Esta dislocación espacial creó y recreó conflictos en la comunidad. Muchos sintieron amenazada una historia de muchos años que veían representada en las figuras de los misioneros británicos.

Los motivos de la mudanza son varios: se resalta que los nuevos dueños del ingenio iban a plantar caña y presionaban con desalojos; también que se abrían posibilidades de vivienda propia en San Pedro para los trabajadores y sus familias; finalmente, algunos pensaron en un presunto complot entre católicos y nuevos dueños. El emplazamiento misionero de Cherenta ocupaba un predio con una posición privilegiada que expresaba el predominio evangélico en la zona. En cuanto a la promesa de viviendas propias, ésta era más que atractiva, puesto que bajo el predominio Leach los trabajadores sólo habían tenido el usufructo de las casillas y galpones acondicionados como tales y en el periodo peronista no parece solucionarse por completo el problema habitacional. En algunos relatos se observa cierto asombro y descontento ante el hecho de que el misionero de los hermanos libre Thomas Easdale hubiera favorecido el ingreso de los bautistas. Como si estos últimos hubieran entrado en escena cuando una generación de guaraníes evangelistas que habían sido socializados en la misión se preparaba para asumir mayores responsabilidades ministeriales. De cualquier modo, las lecturas de este conflicto también se ligan a la actual adscripción denominacional por parte de los protagonistas.

"Se la llevaron con mampostería y todo", recuerda Clemente. Al visitar la iglesia en la ciudad de San Pedro, Donato me indica: "así como usted la ve era la iglesia de Cherenta". Los creyentes de La Esperanza continuaron reuniéndose en casas particulares. Por un tiempo prolongado la casa de los padres de Clemente fue el lugar de culto. A la faz negativa y acusatoria en torno al traslado se le suma otra que la memoria dibuja como un tiempo marcado por la hermandad evangélica; "todos nos juntábamos con todos". Los lugares de encuentro eran las Conferencias, los coros polifónicos y los itinerantes grupos musicales con instrumentos tradicionales. Las conferencias son un espacio de reflexión y encuentro típico de las denominaciones evangélicas. A diferencia de otros grupos, hermanos libres institucionalizaron esta 
modalidad en diferentes escalas (locales, regionales, nacionales) que, al tiempo que servían para la transmisión de "enseñanzas" o preocupaciones doctrinales, recreaban una suerte de ciudadanía evangélica y étnica. De acuerdo a los recuerdos, los misioneros bautistas dieron continuidad a esta práctica que además contaba con un calendario estable como el feriado de carnaval, de pascuas y el de 9 de julio. Fechas oportunamente elegidas para afirmar una pertenencia que se diferenciaba del legitimado catolicismo norteño. En esta época, guaraníes y evangélicos de La Esperanza y San Pedro recuerdan viajes a Yacuy y a Cherenta donde comían choclo "a más no poder" y visitaban a sus parientes. Un hombre originario de La Esperanza recuerda alegremente cuando se desempeñaba como director de un coro. Aunque para entonces vivía en San Pedro y asistía a una iglesia tutelada por los bautistas, el coro que dirigía era de una iglesia distinta, de la denominación pentecostal Iglesia de Dios. Un matrimonio misionero de dicha denominación que vivió en San Pedro entre 1978 y 1982, también recuerda los encuentros compartidos sin distinciones denominacionales. Los recuerdos aquí parecen expresar capas de culturas misioneras apropiadas y traducidas en un tipo de evangelismo que privilegia la pertenencia étnica (guaraní) a las diferencias denominacionales (hermanos libres, bautistas y pentecostales).

Desde fines de 1990, en La Esperanza los creyentes cuentan con nuevo edificio en la calle Esteban Leach destinado a las reuniones de culto. El recuerdo sobre el proceso de gestión de este nuevo edificio parece reubicar a los creyentes en cuadros denominacionales polarizados. Responder a la pregunta de quiénes gestionaron el terreno y el edificio recrea la disputa de quiénes se llevaron el anterior, la iglesia de Cherenta (La Esperanza). Entonces guaraníes que transitaron una hermandad evangélica plausible en recuerdos bien definidos se transforman en bautistas y hermanos libres enfrentados en este plano, que aunque más burocrático en absoluto está carente de significación para las identificaciones locales.

El traslado de la iglesia produjo una inflexión no sólo porque "otros" pudieron llevarse lo que era "propio" del lugar, sino que la ausencia de aquel edificio y la partida de algunas familias a San Pedro implicó en aquellos que se quedaron el largo trabajo de reestructuración material y simbólica. La referencialidad de aquel antiguo culto no es privativa de los actuales creyentes. Un grupo de familias guaraníes de La Esperanza, sellaron un proceso de etnogénesis bajo el nombre de Cherenta. La mentora de esta comunidad con personaría jurídica, como la mayoría de los pobladores, transitó por la escuela dominical. En los últimos años, debido a una fisión en dicha organización, el nombre mudó a Bapurenda, voz guaraní que reverbera las migraciones de sus antepasados desde el oriente boliviano hacia los ingenios del NOA buscando trabajo. Ahora veamos un caso en el occidente chaqueño. Transcribimos e interpretamos especialmente los recuerdos que afloraron en el año 2013 de Ángeles y Pascual, guaraníes y evangélicos de misión Cherenta de Tartagal. De acuerdo a Ángeles, la historia de esta misión se remonta a la década de 1950 cuando su padre, llamado Jacinto,y la familia parten de San Pedro de Jujuy para regresar a Bolivia. Gendarmería impidió que sus hijas de nacionalidad argentina pasaran la frontera. Ante esta imposición, Jacinto resolvió quedarse junto a otras familias en los terrenos conocidos como Tiro Federal (zona en donde los soldados del ejército argentino practicaban tiro al blanco). En aquellos años iban a una iglesia evangélica de los hermanos libres, la misma que habían iniciado en la década de 1930 en Tartagal y que tenía extensiones entre guaraníes de Tiro Federal, Yacuy (Viejo Yacuy), Piquirenda y Aguaray.

En Tiro Federal la familia de Jacinto y otras ligadas se sentían a gusto. La humedad y la vegetación de la falda de aquel cordón montañoso era óptima para vivir y retornar a la agricultura. En 1965 "el hermanito Jacinto fue nombrado como cacique" (Libro de Actas Misión Cherenta). De la mano de él empiezan las gestiones para conseguir las tierras. En 1968 en el marco de una "escasez de agua, vivienda, escasez de todo tipo. Desgraciadamente hubo golpe militar así que ese año no se pudo conseguir nada". Además, los guaraníes fueron desplazados de Tiro Federal como consecuencia de la apropiación de hectáreas por parte del ejército argentino. Ángeles recuerda que su padre toma contacto con Alberto Abraham, por entonces concejal de Tartagal,a fin de reclamar tierras para su comunidad. En una charla este le dijo: "ahora vamos a tener que hacer otra diligencia más (...) vamos a buscar otro terreno". En 1969 aparece un terreno y deben tomar posesión. Ángeles recuerda que inmediatamente los "paisanos" son llamados a mudarse allí: "Se hizo grande Cherenta, mi casa. Él le ha puesto "Cherenta", mi papá. Porque nosotros, él, cuando yo era chica él asistía en la iglesia de Cherenta, ahí en La Esperanza, que era una linda iglesia".

Antes de trasladarse a Cherenta, Ángeles y su familia habían dejado de asistir a la iglesia de la calle Araoz. "Primero estábamos apoyados por una iglesia, que le llaman 'de la calle Araoz'. Después cuando nosotros nos hemos multiplicado muchísimo, como somos guaraníes, así que, éramos muchísimos ya. $Y$ él ya no podía albergarnos ahí en la Araoz". En otro pasaje de nuestra conversación Ángeles insiste y agrega "...después se han alejado, porque ellos [los hermanos libres de calle Araoz] ya le dijeron que no podían con nosotros. Entonces buscaron el apoyo de los misioneros [bautistas], como los misioneros venían siempre para acá."Así también, Ángeles y Pascual dejaron de ir a calle Araoz porque les exigían a los varones ponerse pantalones largos y saco, vestimentas que ellos no tenían. Estos testimonios sugieren varios procesos. Se observa que finalizando la década del '60 y durante los '70, la presencia misionera de los hermanos libres era débil y casi nula -he registrado sólo un 
matrimonio misionero en ese periodo en Tartagal y sus alrededores (Véase Tabla 1)-por el contrario los bautistas venían ganando terreno. También se observa que quienes ocupaban lugares de autoridad entre los hermanos libres tenía poco interés en la evangelización de los guaraníes. Es preciso agregar que la iglesia de calle Araoz en la actualidad tiene un predominio de ascendencia colla en la membrecía y en los lugares de autoridad. Es viable suponer que esa preeminencia, especialmente en los lugares de autoridad, se haya manifestado desde tiempo atrás y que el alejamiento de los guaraníes haya sido en respuesta a fricciones entre grupos étnicos pero también a disputas entre liderazgos. A finales de la década de 1960 ya era común la presencia de misioneros norteamericanos entre los guaraníes y en 1972 se profundiza con su ayuda económica para convertir el antiguo salón de adobe y paja en un culto de cemento.

Los rumbos que han tomado las iglesias de La Esperanza, San Pedro y Tartagal, abordadas aquí, son acentuadamente diferentes. Hoy en día, misión Cherenta (Tartagal) y la iglesia de San Pedro se adscriben bautistas, lo que se refleja en sus formas de gobierno eclesial. Sin embargo, en los rituales de Cena del Señor que incluyen instancias de alabanza y adoración, se observan un profundo sincretismo; que incluye desde el uso del himnario británico hasta performance con rasgos típicos del pentecostalismo indígena pero también de las danzas interétnicas gestadas en los tiempos de zafra de los ingenios. Las iglesias de calle Araoz (de Tartagal) y calle Esteban Leach (La Esperanza), viraron a un fuerte legalismo en cuanto a los aspectos cultuales y doctrinales; se procura la reproducción de ciertas performances rituales que incluyen prescripciones como el uso del velo en las mujeres y la prohibición a su ministerio público. Estas prácticas de tanto en tanto son cuestionadas, especialmente por las nuevas generaciones.

Este escenario de adscripciones denominacionales que pareciera anteponerse a una diversidad de prácticas y creencias efectivamente desarrolladas (Véase Espinosa y Moyano 2017), está estimulado nuevamente por las formas en que el Estado se hizo presente pero también por las transformaciones que experimentaba el campo evangélico que derivaron en redefiniciones de las identidades evangélicas. Como ya hemos adelantado tanto la creación del RNC en 1978 y la posterior fundación de la Sociedad Bautista Misionera (1979) y de la Federación de Entidades Cristianas Evangélicas Argentinas (1988) tuvo efectos variables en la reorganización de las comunidades guaraníes y evangélicas pre-existentes.

Para acceder a una inscripción, la ley exigía una serie de trámites a las organizaciones religiosas como la adquisición de un certificado de antecedentes penales para los ministros religiosos expedido por el Registro Nacional de Reincidencia y Estadística Criminal, requisito que fue derogado en el 2000 (Catoggio 2008). Así también, hasta el 2005 la ley exigía una personaría jurídica que no otorgaba, por lo que las organizaciones debían obtener el estatus de entidades legales por sus propios medios (Frigerio y Wynarczyk, 2008).Sabemos que dichos aspectos fueron especialmente restrictivos para las pequeñas congregaciones diseminadas lejos de los centros de poder y con escaso acceso a instrucciones adecuadas al caso. Aunque se impone la necesidad de un estudio detallado, me animo a indicar que esta fue la situación de muchas iglesias evangélicas guaraníes y criollas del NOA. Algunos aún recuerdan las tediosas idas y vueltas de cartas con la Dirección de Culto entre exigencias burocráticas y rectificación de errores no intencionales. En este sentido, la creación de las federaciones evangélicas bautistas y hermanas libres y la rearticulación de pequeñas iglesias evangélicas diseminadas en una y otra, fueron un medio por el cual evacuar requerimientos legales. Pero a su vez, en el marco de una lucha por la definición de lo evangélico, las federaciones aparecen incidiendo en la configuración del evangelismo étnico; forzando definiciones denominacionales y reactivando redefiniciones identitarias entre los pobladores de estas latitudes. Entre los efectos posibles y escasamente estudiados de esta ley, comprendo que la misma propició una suerte de re-denominacionalización; en definitiva se les exigió a las comunidades -que vivían su religiosidad de maneras menos taxonómica- tener que sellar una identidad evangélica en términos "denominacionales".

Las iglesias de Misión Cherenta de Tartagal (Salta) y la de San Pedro (Jujuy) que se adscriben bautistas, están justamente ligadas a la Sociedad Bautista Misionera. Por otro lado, la iglesia de la calle Esteban Leach de La Esperanza (Jujuy) y la calle Áraoz de Tartagal (Salta), que como dije se reconocen hermanos libres, se ligan organizacionalmente a la FECEA. Algo más para agregar, en San Pedro, una iglesia se inscribió en el RNC como "Iglesia Cristiana Evangélica Bautista Bethel". Las tres primeras palabras de dicho nombre corresponden a la denominación optada por hermanos libres para inscribirse el registro del gobierno peronista. En efecto, este largo nombre lleva inscripto los tránsitos denominacionales pasados, expresa imposiciones pero a su vez adopciones estratégicas en contextos diferentes.

De ningún modo considero que la aparición de estas federaciones haya implicado un reordenamiento automático de las iglesias locales del Noroeste y un consecuente enfilamiento cultual y doctrinal. Las comunidades guaraníes evangélicas tuvieron acciones y representaciones diversas ante el RNC, ante los proyectos pergeñados por los misioneros, las autoridades de las iglesias y estas federaciones. Más allá de los fines de control, en algunos casos las gestiones para inscribirse (o re-inscribirse, dado el antiguo Fichero) fueron percibidas como instancias de legitimación hacia formas históricas de agrupamiento y también como el tránsito obligado por instancias que exigían la ejecución de determinados saberes bajo la presión policial de una posible clausura. También, recordemos que la inscripción 
ofrecía beneficios a dichas organizaciones e iglesias, entre ellas la exoneración impositiva y que los inmuebles sean in-expropiables. Estas condiciones eran conocidas por los creyentes locales.

\section{Conclusiones}

Las misiones evangélicas fueron espacios de transmisión, intercambio e imposiciones culturales $y$, por ello mismo, emprendimientos transnacionales que tuvieron articulaciones locales inéditas que intervinieron en las reconfiguraciones socio-religiosas de diversos grupos étnicos. En el Noroeste Argentino, en particular en la subregión aquí enfocada, la actuación misionera entre los guaraníes estuvo signada por la incorporación de la región al capitalismo mundial y el desarrollo del Estado nacional. Intenté delinear tres momentos de esta articulación que abren una serie de temas específicos y problemas teóricometodológicos para abordarlos.

A principios del siglo $\mathrm{XX}$, los hermanos libres se desplegaron en el marco de una hegemonía liberal que recreaba un Estado subsidiario del capitalismo mundial. Más allá de su faz humanista, el proyecto misionero se desarrolló aprovechando dicho contexto mientras las empresas azucareras se beneficiaban con la cristianización de su fuerza laboral. Al tiempo del arribo de los bautistas observamos otra forma de presencia estatal, con políticas dirigidas tanto hacia las minorías religiosas como hacia las regiones con población predominantemente indígena. Los bautistas tuvieron menos margen de actuación pero afanados en su propósito pudieron negociar el ingreso al campo misionero, ampliándolo. En los años '70 y '80 se evidencia una nueva configuración evangélica, resultado de la apropiación por parte de los guaraníes de la cultura misionera. También se experimenta el influjo de nuevas corrientes evangélicas y los devenires de las políticas de los ingenios. Mientras tanto, no demorarán en aparecer los efectos de la creación del Registro Nacional de Cultos y la fundación de federaciones evangélicas.

No fue mi intención plantear una discusión sobre el concepto de "regulación estatal" o el de "acción misionera". Antes bien, me interesó mostrar cómo, a través del tiempo, las acciones en torno a los grupos indígenas y a las minorías religiosas "definieron fronteras que diseñaron" (Giumbelli, 2016:16) el fenómeno del "evangelismo guaraní" del piedemonte andino y occidente chaqueño del NOA.A lo largo del trabajo busqué un acercamiento histórico al presente etnográfico e intenté analizar el fenómeno apelando a diversos planos interpretativos. Dicho de otro modo, intenté trabajar el material bibliográfico y documental leyendo entrelíneas una dimensión etnográfica y en la etnografía busqué evidencias de las sucesivas "camadas históricas", condensadas y transformadas (Montero, 2006:15). Estrategia delicada que no resuelve el desequilibrio de construir datos para periodos tan disímiles echando mano de fuentes tan escuetas - para el caso de estos fenómenos marginalizados- y de diversa naturaleza.

Sin embargo, creemos que este ejercicio ha permitido dejar planteado que el actual mapa de iglesias indígenas y criollas, bautistas y hermanas libres, y sus configuraciones, no se explican por una sola causa. No es suficiente conocer la presencia bautista, que por más contemporánea es más palpable en la memoria. Tampoco basta con conocer la génesis y el despliegue misionero de los hermanos libres, ni las transformaciones de ambos grupos. En la creación de unas iglesias y la fisión de otras aparece superpuesta la acción de ambos grupos, cuya alianza y posterior diferenciación tampoco es un fenómeno monocausal. De tal modo mostré, por ejemplo, que la actual adscripción denominacional y la pertenencia a un movimiento de etnogénesis no clausura el pasado en una misión evangélica, sino que el mismo es recreado por los actuales pobladores. Así también, intenté evidenciar que el desarrollo de los ingenios y la presencia estatal, a través de la regulación de la diversidad religiosa, intersectaron los planos que condicionaron el accionar misionero y las posibilidades indígenas.

Confinar el pasado a mero contexto que el antropólogo está obligado a narrar, tiene el fatal precio de alimentar la invisibilización de comunidades indígenas que por "menos puras", entre sus impurezas la de ser evangélicas, han permanecido en los márgenes del Estado, de la Nación y de la bibliografía. Así también, postergar el estudio de iglesias evangélicas que por pequeñas y denominacionales estarían destinadas a desaparecer, nos priva de un escenario que enriquece nuestras visiones sobre la diversidad étnica y religiosa en el NOA y sobre el campo evangélico latinoamericano en general. Desde esta perspectiva, histórica y etnográfica, considero fértil la generación de hipótesis sostenibles y duraderas sobre estos temas.

\section{Bibliografía}

Algranti, Joaquín. 2010.Politica y religión en los márgenes. Nuevas formas de participación social de las megas iglesias evangélicas en la Argentina, Buenos Aires: Ediciones CICCUS.

Anónimo. 1923. "Noticias",El Sendero del Creyente, $\mathrm{n}^{\circ} 11$, p.242.

Anónimo.1944."William Charles Kirkby Torre". El Sendero del Creyente, $n^{\circ} 12$, p. 346.

Bevan, Walter. 1972. “Quién tomará su lugar?”. El sendero del Creyente, $n^{\circ} 1$, p. 26.

Bossert, Federico. 2012. "Notas sobre la jerarquía interétnica en los ingenios del Noroeste argentino". En Diego Villar e Isabelle Combès (Eds.) Las tierras bajas de Bolivia: miradas históricas y antropológicas, Santa Cruz de la Sierra: Editorial El país,pp. 217-238. 
Bossert, Federico. 2013. "Ingenios azucareros y relaciones interétnicas". En Sendón, P. y Villar D. (Eds.) Al pie de los Andes. Estudios de etnología, arqueología e historia, Cochabamba: Universidad Católica Boliviana,pp. 163 - 186.

Bossert, Federico y Córdoba, Lorena. 2015. “El trabajo indígena en economías de enclave. Una visión comparativa (barracas caucheras e ingenios azucareros, siglos XIX y XX)". En Córdoba L. Bossert F. Richard, N. (Eds) Capitalismo en las selvas. Enclaves industriales en el chaco y Amazonía (1850-1950), San Pedro de Atacama: Ediciones del Desierto,pp. 111-128.

Bianchi, Susana. 2004. Historia de las religiones en la Argentina. Las minorías religiosas, Buenos Aires: Editorial Sudamericana.

Bisio, Carlos.1982. Nuestros Primeros Pasos, Buenos Aires: Librería Editorial Cristiana.

Bisio, Carlos. (comp). 2007.Congregados en su nombre, Buenos Aires: Librería Editorial Cristiana.

Campi, Daniel (Coord). 1992.Estudios sobre la historia de la industria azucarera Argentina. II. Ediciones del GabineteSecretaría de post-grado Universidad Nacional de Tucumán, pp. 91-112.

Canclini, Arnoldo. 2003. “Unidad y deferencias entre evangélicos argentinos (1825-1945)". Revista Evangélica de Historia vol. 1, pp.11-29.

Catoggio, M. Soledad. 2008. "Gestión y regulación de la diversidad religiosa en la Argentina". En Mallimaci (Coord.) Religión y política, Buenos Aires: Biblos, p. 129.

Ceriani Cernadas, César. 2015a. "Flujos teóricos y transformaciones empíricas en el estudio de los pueblos indígenas del Chaco argentino", Papeles de Trabajo, 9 (16), pp.110-151.

Ceriani Cernadas, César. 2015b. “Campanas, capitanes y evangelios. La circulación religiosa indígena en los ingenios del Norte Argentino". En Córdoba L. Bossert F. Richard, N. (Eds) Capitalismo en las selvas. Enclaves industriales en el chaco y Amazonía (1850-1950), San Pedro de Atacama: Ediciones del Desierto, pp.45-64.

Ceriani Cernadas, César. 2017. “Misión, nación y religión. Las fronteras del dios Chur entre los toba formoseños". En Ceriani Cernadas, C. (Dir) Misiones Cristianas y pueblos indígenas en el Chaco Argentino. Buenos Aires: Colección Ethonographica, Editorial Rumbo Sur (en prensa).

Clifford, Juan. 1972. "Con el Señor". El Sendero del Creyente, n¹, pp. 24-26.

Clifford A.1972. El Sendero del Creyente, n5, pp. 130-131.

Damboriera, Prudencio.1963. El protestantismo en América Latina (tomo II). Madrid: Oficina Internacional de Investigaciones Sociales de FERES

Demera, J. D. 2009. "Transformaciones socioculturales y dinámicas protestantes en el campo étnico latinoamericano". Religiones y Cultura. Perspectivas latinoamericanas. Buenos Aires: Biblos.
Di Stefano, R. y Zanatta, L. 2000. Historia de la Iglesia Argentina, Buenos Aires: Grijalbo.

Easdale, Donald. 1988. "Los esposos Easdale entre los chiriguanos" En Manrique Zago (comp) Jujuy,San Salvador de Jujuy: Manrique Zago Ediciones,p.93.

Espinosa, Mariana. 2014. “Una iglesia primitiva e internacional: el perfil misionero de los Hermanos Libres en su llegada a la Argentina". Ciencias Sociales y Religión/Ciências Sociais e Religião, Porto Alegre, Ano 16, 20 (1), pp. 58-81.

Espinosa, Mariana. 2015. "Indígenas y misioneros: génesis y representaciones de una misión evangélica en el ingenio La Esperanza". Revista Brasileira História das Religiões, Maringá, v. $8, n^{\circ} 22$, pp. $125-143$.

Espinosa, Mariana. 2017. “Fragmentos más o menos guaraníes sobre el evangelio en La Esperanza". En Ceriani Cernadas, C. (Dir) Los evangelios chaqueños. Misiones y estrategias indígenas en el siglo xx, Buenos Aires: Editorial Rumbo Sur (en prensa).

Espinosa, Mariana y Moyano Alejandro. 2017. “Más o menos guaraníes o más o menos evangélicos? Notas sobre (la) cosmología de pobladores de tierras bajas jujeñas". Ponencia presentada en IX Jornadas internacionales Ciencias Sociales y Religión, CEIL-CONICET, Facultad de Ciencias Sociales, UBA, Noviembre.

López Fidanza, Juan Martín. 2014. "Regulación estatal y minorías religiosas: el culto a San La Muerte". En Flores F. y Seiguer P. Experiencias plurales de lo sagrado. La diversidad religiosa argentina. Buenos Aires: Imago Mundi, pp.127-146

Frigerio, Alejandro y Wynarczyk, Hilario. 2008. "Diversidad no es lo mismo que pluralismo: cambios en el campo religioso argentino (1985-2000) y lucha de los evangélicos por sus derechos religiosos". En Sociedade e Estado, Brasília, v. 23, n 2, pp. 227-260.

Giumbelli, Emerson. 2016."Regulação do religioso: discussões conceituais e panorama da situação em quatro países latinoamericanos". Ciências Sociais e Religião, Porto Alegre, ano 18, $\mathrm{n}^{\circ} 25$, pp. $14-37$.

Gómez, Mariana. 2010. “¿Bestias de carga? Fortaleza y laboriosidad femenina para el capital. La incorporación de las mujeres indígenas en el trabajo en los ingenios" en Citro, Silvia (coord.) Cuerpos Plurales. Ensayos antropológicos de y desde los cuerpos, Buenos Aires: Biblos, pp. 239-256.

Gordillo, Gastón. 2010a.Lugares de Diablos. Tensiones del espacio y la memoria, Buenos Aires, Prometeo.

Gordillo, Gastón. 2010b. "Deseando otro lugar: Reterritorializaciones guaraníes". En Gordillo, G y S. Hirsch, Movilizaciones indígenas e identidades en disputa en la Argentina, Buenos Aires:La Crujía,pp.207-236.

Hirsch, Silvia. 2004. "Mbaporenda: el lugar donde hay trabajo. Migraciones guaraníes al Noroesteargentino". Etnohistoria. http://etnohistoria.equiponaya.com.ar/htm/04_ articulo.htm(última consulta: 2/09/2017).

Jack, Roberto. 2007. "Argentina en la cuenca del Plata". En Bisio, 
Carlos. En Congregados en su nombre.Buenos Aires: Librería Editorial Cristiana,p. 167-170

Jerez, Marcelo A. 2010. Las políticas sociales del primer peronismo jujeño y su implicancia socio-política en la ciudad de San Salvador de Jujuy (1946-1955), Tesis de Doctorado en Historia. Facultad de Filosofía y Letras, Universidad Nacional de Tucumán.

Junta Bautista de Publicaciones. 1959. En marcha. 50 Aniversario de la Convención Evangélica Bautistas de la Argentina.

Langer, Erick. 1995. "Missions and frontier economy: the case of the franciscan missions among the chiriguanos, 1845-1930". En Langer and Jackson (Eds) The new latinamerican mission history, Lincoln and London University of Nebraska Press, pp. 49-75.

Lozano, Claudia. 2001. Misioneros cristianas y población con raíces indígenas: un debate sobre la identidad y las diferencias en el noroeste argentino, Berlin: Wissenschaftlicher Verlag Berlin.

Lunt, Roberto. 2011. Cien años de la misión anglicana en el norte argentino 1911-2011, Ingeniero Juárez, Formosa: Edición Diócesis de la Iglesia Anglicana en el Norte Argentino.

Míguez Bonino, José. 1995. Rostros del protestantismo latinoamericano. Buenos Aires: Nueva creación.

Montani, Rodrigo. 2015. “El ingenio como superartefacto: Notas para una etnografía histórica de la cultura material wichí". En Córdoba L. Bossert F. Richard, N. (Eds) Capitalismo en las selvas. Enclaves industriales en el chaco y Amazonía (1850-1950), San Pedro de Atacama: Ediciones del Desierto, pp.19-44.

Montero, Paula (org). 2006. Deus na aldeia. Missionários, índios e mediação cultural. São Pablo: Editora Globo.

Payne, Will [Guillermo]. 1923. "Ernesto Heycook". El Sendero del Creyente, $n^{\circ} 5$, p.107.

Pérez Bugallo, Nahuel. 2013. Historia, memoria y pasado reciente entre los guaraníes de la Misión San Francisco. En Sendón, P. y Villar D. (Eds.) Al pie de los Andes. Estudios de etnología, arqueología e historia, Cochabamba, pp. 153-162. Cochabamba: Universidad Católica Boliviana.

Powell, David. 1998. La historia que faltaba, El protestantismo en Tucumán, Buenos Aires: Co-edición Instituto de Historia y Pensamiento Argentinos y Editorial Kairós.

Roldan, Alberto. 1996. La comprensión de la realidad social en el discurso teológico de los hermanos libres en la Argentina (1882-19559), Tesis Doctoral de Teología, ISEDET.

Rutledge, lan. 1987. Cambio agrario e integración. El desarrollo del capitalismo en Jujuy: 1550-1960, Tucumán: Co-edición ECIRA y CICSO.

Santamaría, Daniel J. 1992. "Migración laboral y conflicto interétnico. El caso de los migrantes indígenas temporarios en los ingenios saltojujeños". En Campi, Daniel (Ed) Estudios sobre Ia historia de la industria azucarera Argentina, II. Ediciones del Gabinete- Secretaría de post-grado Universidad Nacional de Tucumán, pp. 91-112

Shank, J. 1944. My Chaco Diary. Mimeo, Indiana, Mennonite Board Missions.

Segato, Rita. 2007. "Cambio religioso y des-etnificación: la expansión evangélica en los Andes Centrales de Argentina". La Nación y sus Otros: raza, etnicidad y diversidad religiosa en tiempos de políticas de la identidad, Buenos Aires: Prometeo,pp. 243-272.

Stunt, W.T., Pulleng A., Pickering A., Simmons G. P., Boak D. K., Warren S.F. 1972. Turning the world upside down, Bath: Echoes of service, Upperton press.

Tatford, Fredic A. 1982. A new day in Argentina, Centrenary 1882-1982, Bath: Published by Echoes of service and Printed By Ebdons.

Wright, Pablo. 2002. "L' "Evangelio": pentecôtisme indigène dans le Chaco argentin". Social Compass 49 (1), pp. 43-66. Wynarczyk, Hilario.1993. "Carlos Annacondia: Un estudio de caso en neopentecostalismo", en Frigerio, Alejandro (editor) Nuevos movimientos religiosos y Ciencias Sociales (II), Buenos Aires: Centro Editor de América Latina,pp. 80-97.

Wynarczyk, Hilario y Semán, Pablo. 1995. “Un análisis del campo evangélico y el pentecostalismo en la Argentina", en Panorama actual del campo evangélico en Argentina. Un estudio sociológico, Buenos Aires:Facultad Internacional de Educación Teológica (versión digital),pp. 4-18 